\title{
LA MANIFESTACIÓN DE LO GENERAL EN LA COMEDIA SEGÚN ARISTÓTELES*
}

\author{
Luis Cifuentes Acuña \\ Universidad de Chile \\ cifuac@gmail.com
}

\section{RESUMEN / ABSTRACT}

El presente trabajo tiene por objeto ofrecer una mirada sobre la idea de generalidad en la comedia que Aristóteles desarrolló fragmentaria y sucintamente en la Poética a través de un esquema de desarrollo del género.

Considerando que Aristóteles concibe a la poesía como una actividad mimética artística en donde lo general o universal ${ }^{* *}$ tiende a ser un elemento definitorio de su constitución como un tipo especial de experiencia, se expondrán sus fundamentos y características que nos permitirán comprender la comedia como la realización particular de un tipo de expresión de lo general. Para afirmar finalmente que en el intento de Aristóteles por trazar una idea de la comedia en oposición a la forma precedente de la invectiva, lo general será el criterio fundamental para entender algunos conceptos clave del género (como lo risible), además de respaldar su vinculación con aquellas obras cómicas correspondientes a la comedia Nueva.

PALABRAS ClaVE: mímesis, general, comedia, invectiva, risible.

Este artículo fue realizado dentro del marco de financiamiento para estudios de postgrado otorgado por CONICYT-PCHA/MAGISTER NACIONAL/2013-221320850.

** En este artículo, muchas veces el término "universal" reemplaza al término "general" presente en el título. No obstante, los utilizo indistintamente considerando que entre ambos no hay variación significativa alguna. Así, la elección por el término "general" en el título se debe más que nada al respeto por la traducción de García Yebra de la Poética (Ed. Gredos, Madrid, 1974) que es la que uso al momento de citar dicho texto de Aristóteles. 
This work attempts to offer a view on the Aristotle's idea of generality in comedy, idea developed fragmentarily in his Poetics through a schematic history of the genre.

Considering that Aristotle conceives of poetry as a mimetic activity where the general tends to be a defining element in its being a special kind of experience, in this work I will show its grounding and specific features wich will lead us to understand comedy as a specific type of expression of the general. All this will finally lead us to affirm that in Aristotle's purpose to construe an idea of comedy as opposite to the previous comic form of the lampoon, the general will be a fundamental criterion to understand some key concepts of the genre (as the laughable) and its relationship with New Comedy plays.

Keywords: mimesis, general, comedy, lampoon, laughable.

\section{SEMEJANZA Y SIMPATÍA EN LA MÍMESIS}

Dice Aristóteles que la epopeya, la tragedia y la comedia, que son los géneros poéticos de los cuales trata principalmente la Poética ${ }^{1}$, se definen como imitaciones realizadas mediante lenguaje, ritmo y armonía (Aristóteles, Poética 128). Si eludimos los términos peyorativos que utiliza Platón para referirse a la imitación o mímesis ${ }^{2}$, subyace como fundamento de la eficacia imitativa la estructuración de ésta en términos de modelo-copia. El modelo visual de "semejanza" significa, tal como señala Halliwell, la ilustración paradigmática del principio de reconocimiento y comprensión atribuido a la mímesis y que

1 Sin embargo, Aristóteles ha prometido tratar la comedia con mayor extensión en un segundo libro que se ha perdido.

2 Para Platón, la mímesis sirve de explicación para relacionar los dos ámbitos que dentro de su doctrina se hallan separados: el mundo de las ideas (los modelos eternos llamados paradigmas) y el mundo sensible; siendo el último una imitación de los paradigmas del primero en un sentido que implica una degradación y lejanía de lo real y esencial, tal como se expresa en el capítulo X de La República. Además, allí, la mímesis se discute dentro del proyecto de una ciudad saludable y se considera un lujo y no una necesidad. En el capítulo III, dos son los motivos por los cuales se condena la mímesis. Primero, porque en las representaciones dramáticas se invita a jugar a los ciudadanos un rol distinto de los ya asignados para el buen funcionamiento de la polis. Y segundo, porque el autocontrol que los guardianes deben tener es puesto en peligro por las expresiones emocionales en el teatro, ya sean: la aflicción o la compasión en la tragedia o los insultos y las obscenidades en la comedia (Reckford 367-368). Así, la mímesis es separada de lo racional, esencial y verdadero, y es vinculada a lo emocional (considerando las emociones que suscitan las representaciones dramáticas y sus efectos perjudiciales en una vida guiada por la razón) y por lo tanto, a lo potencialmente perturbador (Potolsky 18). 
podemos ver expuesto en el capítulo 4 de la Poética. Allí, Aristóteles propone la mímesis como una tendencia natural en el hombre, mediante la cual éste adquiere sus primeros conocimientos y por la cual también siente placer ${ }^{3}$. Ya sea el hecho de que nos guste ver ejecutadas "con la mayor fidelidad posible" (136) las imágenes de seres (cadáveres y los animales más repugnantes) cuyo aspecto en la realidad nos molestaría, o el hecho de sentir placer porque al contemplar las imágenes se aprende y deduce qué es cada cosa, "por ejemplo, que éste es aquel" (136), en ambas situaciones está implicada la idea de una semejanza entre una representación y su objeto, que en el caso de la pintura, correspondería a las formas y colores de la representación con las formas y los colores del objeto representado ${ }^{4}$. Pero la mímesis no es solo un asunto que atañe a los contenidos de la representación sino también a la relación que establece con las propias experiencias de los oyentes. Bajo este sentido surge la idea de "simpatía", de la cual se vale Platón para condenar las representaciones dramáticas como la tragedia. Porque los espectadores que conforman la audiencia, al dejarse llevar por las emociones, imitan en privado los sufrimientos que ven en escena, amenazando el predominio que la razón debería tener sobre nuestros comportamientos. De esta manera, como señala Potolsky, “desde la creación a la recepción, el arte y su influencia están definidos por la mímesis" (28).

\section{LO GENERAL COMO OBJETO DE LA MÍMESIS POÉTICA}

La poética, como un tipo de arte, se define por la imitación de acciones humanas mediante lenguaje, ritmo y armonía. En cuanto a sus especies

Aunque, como ha señalado García Yebra (254), no se puede limitar el placer de la mímesis únicamente a una razón intelectual de aprendizaje, puesto que hay que considerar los dos placeres que surgen de las propiedades no-representacionales de la obra mimética: 1) la destreza artística que produce la fidelidad con el modelo (Aristóteles, Poética 136) y 2) las propiedades sensuales del artefacto (Aristóteles, Poética 136).

Existe una mímesis icónica en virtud de las propiedades intrínsecas que los medios comparten con los objetos que representan. Como dice Halliwell, este factor de coincidencia perceptual serviría, en el caso de la pintura (y concretamente a través del ejemplo del retrato: "que éste es aquel" (Aristóteles, Poética 136)) para hacer más explícita la idea de reconocimiento y comprensión presentes en las representaciones miméticas artísticas (Halliwell, The aesthetics of Mimesis 158). 
(epopeya, tragedia, comedia, ditirambo, etc.), estas se diferencian ya sea por el modo o por el objeto de imitación. Tragedia y comedia se distinguen de la epopeya porque la última imita narrando (ya sea hablando en boca de un personaje -lo que, para Aristóteles, hace a Homero un buen poeta- o hablando uno mismo y sin cambiar (Aristóteles, Poética 133)), mientras que las primeras imitan "presentando a todos los imitados como operantes o actuantes" (Aristóteles, Poética 133). No obstante, se diferencian por el objeto de imitación. La tragedia imita hombres mejores que los reales; la comedia, peores. Agregando que, en efecto, los caracteres son posibles de reducir a estas dos categorías, ya que "todos sobresalen, en cuanto al carácter, o por el vicio o por la virtud" (Aristóteles, Poética 131). Si bien el reconocimiento y la comprensión en la mímesis que expresa el capítulo IV está ejemplificado principalmente por el retrato, de ninguna manera se puede limitar a este último si lo consideramos en un sentido moderno ${ }^{5}$, ya que el objeto en la poesía, en esta primera aproximación, es lo general (desde los cánones de necesidad y verosimilitud) de sus tres objetos: la acción, el carácter y pensamiento ${ }^{6}$, y no lo particular o individual real que es más bien propio de la historia. Como señala Aristóteles en el capítulo 9 de la Poética: "la poesía dice más bien lo general, y la historia, lo particular. Es general a qué tipo de hombres les ocurre decir o hacer tales o cuales cosas verosímil o necesariamente, que es a lo que tiende la poesía, aunque luego ponga nombres a los personajes; y particular, qué hizo o qué le sucedió a Alcibíades" (158). De esta distinción, como expresa Halliwell, se pueden extraer dos consideraciones importantes. Primero, que la historia, vista desde esta perspectiva, es considerada por Aristóteles como

Tal como expresa Gomá Lanzón, en la antigüedad griega ni la escultura ni la pintura eran realistas en el sentido moderno de retratar a cosas o personas singulares; al contrario, sus modelos eran ideales o paradigmáticos. "Las esculturas griegas no aspiran a representar a un atleta individual o a un político de la época, sino el ideal del atleta o del político, escogiendo, como refiere Jenofonte, de entre los diversos modelos concretos históricos lo más conveniente y más perfecto" (131).

Como queda evidenciado en el capítulo 6 de la Poética (en la mención de las partes de la tragedia), tres son los objetos de la mímesis (147), siendo el más importante "la estructuración de los hechos; porque la tragedia es imitación, no de personas, sino de una acción y de una vida, y la felicidad y la infelicidad están en la acción, y el fin es una acción, no una cualidad. Y los personajes son tales o cuales según el carácter; pero, según las acciones, felices o lo contrario. Así, pues, no actúan para imitar los caracteres, sino que revisten los caracteres a causa de las acciones. De suerte que los hechos y la fábula son el fin de la tragedia, y el fin es lo principal en todo" (147-148). 
una disciplina de investigación con un estatuto equivalente al de la ciencia; teniendo ambas por objeto lo real. En efecto, como se puede comprobar en el capítulo 25, se exime a la poesía del criterio de verdad, ya sea porque Aristóteles se niegue a censurar, como sí lo hace Platón ${ }^{7}$, el manejo erróneo por parte del poeta de aquellos conocimientos técnicos como el de la medicina, considerándolo como un error accidental y no consustancial al arte poético (226), o por admitir lo imposible 8 , o lo contrario a la verdad, considerando la importancia de lo verosímil o lo ejemplar en el arte poético ${ }^{9}$. Segundo, en la historia predomina la contingencia, es decir, los acontecimientos que no poseen un encadenamiento necesario o verosímil, "lo que la hace inapropiada para los argumentos unitarios sobre los que la teoría de Aristóteles insiste" (Halliwell, The aesthetics of Mimesis 165) ${ }^{10}$. Tal como señala el mismo Aristóteles, quien reiteradamente concibe lo universal (o general) en conexión con lo necesario o verosímil (Aristóteles, Poética 158; 189), la acción en la poesía debe ser entera o completa y tener cierta magnitud (Aristóteles, Poética 153). Entendiendo por entero que posea principio, medio y fin (Aristóteles, Poética 152). Y entendiendo por magnitud-considerando la analogía entre la acción poética y un animal bello ${ }^{11}$ - el tamaño suficiente para poder captar la unidad y la totalidad del objeto, es decir, lo suficiente para poder recordar fácilmente la fábula que debería abarcar, en la sucesión verosímil y necesaria

7 "Platón, República X 599-600, censuraba a Homero porque, desconociendo la medicina, la estrategia, la política, etc., aparentaba en sus cantos conocer estas artes" (García Yebra 326).

"Se han introducido en el poema cosas imposibles: se ha cometido un error; pero está bien si alcanza el fin propio del arte [...] si de este modo hace que impresione más esto mismo u otra parte" (Aristóteles, Poética 227).

"si se censura [que el poeta] no ha representado cosas verdaderas, pero quizá las ha representado como deben ser, del mismo modo que también Sófocles decía que él presentaba a los hombres como deben ser, y Eurípides como son, así se debe solucionar el problema. Y [...] puede aún contestarse que así se dice, por ejemplo las cosas relativas a los dioses; pues quizá no se representen mejor ni de acuerdo con la verdad, sino como le pareció a Jenófanes" (Aristóteles, Poética 228).

10 Esta misma exigencia de unidad de acción sobre la base de la probabilidad y la necesidad le permite a Aristóteles diferenciar la epopeya de los relatos históricos, ya que en estos últimos "se describe no una sola acción, sino un solo tiempo, es decir, todas las cosas que durante él acontecieron a uno o a varios, cada una de las cuales tiene con las demás relación puramente casual" (Aristóteles, Poética 215).

11 Para el concepto de belleza en Aristóteles, concebido como magnitud y orden, ver: Metafísica, Libro XIII (1078a 36-37), Ética a Nicómaco (1123b 7) y Política (1326a 33). 
de sus acontecimientos, "la transición desde el infortunio a la dicha o desde la dicha al infortunio" (Aristóteles, Poética 155).

\section{LA MÍMESIS POÉTICA Y SU COMPRENSIÓN FILOSÓFICA DE LA REALIDAD}

El último aspecto revisado, centrado en la experiencia estética de la mímesis poética, traslada la importancia desde las propiedades objetivas de lo bello hacia la percepción. En este caso, la facilidad en la percepción de la unidad (la construcción del argumento en torno a una acción única) coadyuva al placer y la satisfacción propios de la comprensión ${ }^{12}$. Y ésta, como vimos en el esquema cognitivo del placer mimético, implica un reconocimiento fundado en la semejanza. Tal semejanza, ateniéndonos a la distinción entre historia y poesía, generalmente no es con un particular real, y tampoco implica el mero registro pasivo de algo ya existente, sino que la comprensión de una realidad probable o necesaria que nos otorga una experiencia sobre el mundo a partir de patrones de realidad. Como dice Halliwell:

Cuando observamos casos comunes de semejanza, observamos propiedades o cualidades comunes. Cuando nos relacionamos apreciativamente con obras miméticas, reconocemos y comprendemos las maneras en que los posibles rasgos de la realidad, las posibles formas de experiencia humana, están intencionalmente significadas y encarnadas en aquellas (Halliwell, The aesthetics of Mimesis 189).

Por lo tanto, el proceso de comprensión en la obra mimética implica no solo la conciencia de la artificialidad de la realidad que ésta nos presenta sino también de los rasgos comunes que esta realidad hipotética comparte

12 Aristóteles percibía más bien la belleza en las cosas particulares que en los conjuntos. En esto se puede ver la incidencia de las cualidades de proporción y armonía para determinar la belleza, ya que aquellas son más visibles, por ejemplo, en criaturas particulares que en paisajes. "Fueron los romanos los que mostraron predilección por los paisajes, mientras que los clásicos se deleitaban con objetos aislados, más transparentes, perceptibles y limitados, en los cuales se veía con más claridad, la proporción, la medida y la unidad" (Tatarkiewicz 160). Y García Yebra, citando un pasaje de Problemas (XVIII, 9, 917b 10-12), expone que para Aristóteles la satisfacción que nos producen las historias que tratan de una sola cosa en vez de muchas se debe a que estas son más comprensibles (272-273). 
con la nuestra. Ambas posturas se encuentran expresadas por Aristóteles en relación con el placer de las obras miméticas. En la Retórica $(114)^{13}$, al igual que en la Poética (136), el placer depende de la representación misma, considerando que lo representado en la realidad no debería despertar placer alguno, como sucede con la visión de animales repugnantes, cadáveres o cosas, en general, no placenteras. En efecto, se disfruta al reconocer lo bien imitado del modelo. O, como expresa Potolsky teniendo en vista los sentimientos de temor o compasión suscitados por la tragedia, mediante el "desapasionamiento" de considerar que los efectos de aquellas emociones son distintos a los de la vida cotidiana ${ }^{14}$. Mientras que en la Política $(171)^{15}$ el placer se encuentra relacionado directamente con la experiencia de placer en la realidad. De manera equivalente sucede con la tragedia, si consideramos que la imitación de acontecimientos penosos y temibles tiene por finalidad el inspirar compasión y temor. Por eso, como expresa Halliwell:

Las respuestas a las obras miméticas deberían siempre descansar (si ellas son respuestas a la mímesis como tal) en el reconocimiento cognitivo del significado de la representación, y en consecuencia serían instruidas por la experiencia de realidades comparables con el mundo en general; pero también tales respuestas constituyen una reacción compuesta a, y hacen posible una interacción entre, el contenido representacional y su representación artística (The aesthetics of Mimesis 185).

13 "Y como es placentero aprender y admirarse, es forzosamente placentero tanto lo que imita, como ocurre con la pintura, la escultura y la poesía, como todo lo que está bien imitado, incluso si lo que se imita no es placentero, pues no es con esto con lo que se goza, sino que hay un razonamiento del tipo "esto es aquello", y en consecuencia resulta que se aprende" (114).

14 "Los efectos de compasión y temor que experimentamos en el teatro, si bien son genuinos, difieren de los efectos de aquellas emociones en la vida diaria. En otros contextos, podríamos correr de algo que tememos, u ofrecer ayuda al objeto de nuestra compasión. Pero tal como la mímesis nos permite ver cuerpos muertos desapasionadamente, también nos permite experimentar nuestras emociones de la misma manera, para disfrutarlas más que sufrir o reaccionar por ellas" (Potolsky 44).

15 "El hábito de sentir placer o dolor en las meras representaciones no está alejado de sentir lo mismo en la realidad; por ejemplo, si alguien disfruta de la contemplación de una estatua sólo por su belleza, necesariamente se sigue que la contemplación del original le será placentera" (171). 
De este modo, si alguna idea de ficción se deduce de la separación entre la poesía y la historia, al tratar la primera sobre lo que podría suceder, "esto es, lo posible según la verosimilitud y la necesidad" (Aristóteles, Poética 157) y no sobre lo sucedido, como hace la segunda, esta en modo alguno puede concebirse como una pseudorrealidad engañosa a la manera de Platón. Al contrario, al ser "más filosófica y elevada que la historia" (Aristóteles, Poética 158), en virtud del argumento unitario que construye, y por el cual se expresan los universales, se esperaría de la poesía la entrega de una comprensión más profunda de la realidad. Sobre todo si el mundo posible que despliega, por efecto de los mismos universales que encarna, se halla unido a causas, razones y motivos que dan cuenta de una inteligibilidad de la acción humana.

\section{LA MANIFESTACIÓN DE LO GENERAL EN LA POESÍA A TRAVÉS DE PARTICULARES IMAGINARIOS}

La tensión entre poesía e historia no se resuelve simplemente identificando la primera con el discurso filosófico. Pues la poesía trata, a pesar de la generalidad implicada, con caracteres que corresponden a particulares imaginarios, ya que tienen nombres y llevan a cabo acciones individuales en situaciones específicas. Es por este motivo que Aristóteles recomienda a los poetas, al momento de estructurar las fábulas, ponerse en lugar del espectador y hacer como si los hechos se estuvieran desarrollando ante sus propios ojos, con el objeto de hallar lo apropiado y poder advertir las posibles contradicciones (Aristóteles, Poética 187). Existe, por ende, un factor de vivacidad presente en la ficción dramática que impide concebirla como una imitación de abstracciones. En este sentido, Halliwell expresa que conviene pensar los universales en la mímesis poética como un punto intermedio entre la abstracción y la experiencia de sentido común (Halliwell, The aesthetics of Mimesis 194). No como propiedades explícitas del poema ni menos de carácter proposicional. Los universales poéticos no son parte del contenido reflexivo y moralizador de los discursos de los personajes, ya que esto último debería ser cubierto por el término dianoia (Aristóteles, Poética 195) que, como dice Aristóteles, corresponde más bien a la Retórica. En la Poética, los efectos apropiados deben conseguirse mediante los hechos, es decir, deben nacer de la acción misma sin necesidad de "declaración explícita" 
o enseñanza ${ }^{16}$, como corresponde al discurso del que habla ${ }^{17}$. El idealismo del arte imitativo, como expresa Gomá Lanzón, no representa una vuelta al mundo de las ideas platónicas, ya que "no es lo mismo la Idea del hombre que el hombre ideal, la imitación del concepto abstracto que la imitación de la Naturaleza por medio de la representación sensible de un tipo ideal" (132). Lukács se expresa de una manera similar al establecer una dialéctica entre lo general y lo particular en su concepción del realismo estético. Para él, el arte, al igual que el reflejo de la realidad mediante categorías de pensamiento, es capaz de expresar leyes generales sobre los fenómenos del mundo. Pero se debe evitar ver en esta expresión de lo general por parte de la forma artística una oposición a lo particular e individual. De esta manera, sería errado considerar que lo general es solo una expresión del contenido aislado de la forma artística que le ha servido de "medio técnico auxiliar" para su expresión. O, también, concebir lo general solo como un "aditamento mental y abstracto" sin una vinculación orgánica al mundo sensible de la obra. Citando el capítulo 9 de la Poética, argumenta que la conciencia del proceso generalizador en el arte consiste en que lo general o esencial aparezca manifestado en lo particular y fenomenal, coincidiendo ambos en una unidad espontánea. Así, por ejemplo, el reflejo del detalle sería un reflejo justo de la vida, no a causa de que ese detalle se encuentra plasmado en la realidad, es decir, de que tenga carácter referencial, sino porque sería capaz de reflejar el conjunto de la realidad objetiva. Por lo tanto, las determinaciones esenciales de lo concreto, por las cuales se expresan las leyes generales de la naturaleza y la vida, "han de aparecer [...] como propiedades concretas, directas y sensibles de los distintos individuos, situaciones, etc." (Lukács 28). En síntesis, si los universales están presentes en la obra poética, lo están de manera implícita, como propiedades encarnadas en la ficción dramática concreta y particular, mediados por la estructura del argumento unitario, y por lo tanto en dependencia de una compresión interpretativa activa por parte del espectador u oyente (Halliwell, The aesthetics of Mimesis 198).

17 En un mismo sentido se puede relacionar la prohibición por parte de Aristóteles de que el poeta hable personalmente en el poema en vez de hacer hablar a sus personajes, "pues, al hacer esto, no es imitador" (Aristóteles, Poética 221). En esto Homero se destacó de los demás poetas. "Aristóteles quiere conducir la poesía lejos de la declaración didáctica, en efecto de la "declaración" - la voz autorial- a secas, que parece considerar estrictamente incompatible con la mímesis" (Halliwell, The aesthetics of Mimesis 198). 
Como podemos apreciar en el caso de la tragedia, según Potolsky, a pesar de las emociones que provoca, hay un componente profundamente racional en ella, tanto en su configuración como en las respuestas que exige para su comprensión. Mientras que para Platón las emociones suscitadas por la tragedia son completamente irracionales, Aristóteles les da un fundamento racional. Ya sea como emergidas de la fábula (unidad de acción que incluye acontecimientos penosos y temibles) así como reconocidas por medio de procesos cognitivos (como los implicados en la compasión y el temor ${ }^{18}$ ) lo que se sugiere es la exigencia de una operación activa de interpretación. "La tragedia no sólo confirma sus audiencias en la comprensión existente del mundo. Esta provee a aquellos con oportunidades imaginativas para probar, perfeccionar, extender, y quizás incluso cuestionar las ideas y valores sobre los que tal comprensión descansa" (Halliwell, The aesthetics of Mimesis 201).

\section{LO RISIBLE COMO SIGNO DE LO GENERAL EN LA COMEDIA: UNA EVOLUCIÓN DEL GÉNERO}

Considerando que la comedia se define también como una especie de la Poética, ésta debería satisfacer los mismos criterios que Aristóteles expone para los géneros serios. La comedia, al igual que la tragedia, derivaría de los instintos miméticos del hombre. Y debería, de igual manera, proporcionar una experiencia que en parte es cognitiva y de aprendizaje, cumpliendo para ello con el canon de unidad de su argumento por el cual la "vivacidad"19 de las acciones imaginarias que representa adquieren una inteligibilidad de acuerdo a lo general o universal. En este sentido, la comedia imita las acciones adecuadas a los hombres inferiores ${ }^{20}$, pero, como dice Aristóteles en

18 La compasión es reconocida cuando uno percibe que una desgracia que afecta a alguien es inmerecida, mientras que el temor se reconoce al proyectarnos nosotros mismos en la situación del personaje (Aristóteles, Poética 173-174).

19 Como se expresa en el capítulo 17 de la Poética: "Es preciso estructurar las fábulas y perfeccionarlas con la elocución poniéndolas ante los propios ojos lo más vivamente posible" (187).

20 La dicotomía entre los caracteres de la tragedia ("mejores que los hombres reales" (Aristóteles, Poética 132)) y los de la comedia ha sido, según Halliwell, comúnmente tratada por la crítica basándose en la categoría del rango social. Pero Aristóteles no puede ser confinado absolutamente bajo este criterio. Primero, porque dentro de los caracteres cómicos, la variedad 
el capítulo 5, "no en toda la extensión del vicio, sino que lo risible es parte de lo feo. Pues lo risible es un defecto y una fealdad que no causa dolor ni ruina; así sin ir más lejos, la máscara cómica es algo feo y contrahecho sin dolor" (141-142). Según Halliwell, Aristóteles está interesado en trazar un patrón de evolución poética para la comedia, tal como la ha hecho para la tragedia, considerando la forma paralela de la argumentación en los capítulos 4 y 5 (Halliwell, Aristotle's Poetics 269). Desde esta perspectiva, naciendo la poesía de improvisaciones ${ }^{21}$, los géneros se desarrollan hasta alcanzar su propia naturaleza. En el caso de la comedia, los que antes componían yambos (invectivas) pasaron a hacer comedias, teniendo como estímulo el Margites de Homero; pues allí, como el mismo Aristóteles señala, se presentaba en acción "no una invectiva, sino lo risible"(138) ${ }^{22}$. Estos dos términos, efectivamente, permiten trazar el esquema de desarrollo cómico contraponiéndolos como etapas sucesivas dentro de la evolución del género. La invectiva (psogos), como lo prueba la obra de Cratino, fundaba toda su fuerza y prestigio en la "sátira regocijada contra personajes políticos de notoria impopularidad" (Jaeger 329). Y este elemento de burla contra particulares se mantiene en la comedia antigua de Eupolis y Aristófanes. Como señala Aristóteles en la Ética, quien intenta proponer un tipo de humor adecuado a los hombres elegantes y generosos, a menudo aquellos quienes se exceden en lo risible no se preocupan ni de hablar con decoro ni de no dañar a quienes son objetos de sus burlas (148). Así, Aristóteles separa a los que bromean, teniendo en cuenta su elaboración de la definición de justo medio, en dos tipos: los

alcanza a héroes y dioses; y segundo, porque el lenguaje utilizado para aludir al carácter (ethos) tiene implicancias morales. "Los géneros son separados, en la formulación teórica de Aristóteles, principalmente por el carácter y el tono [este último término, que corresponde al decoro del Renacimiento, no es aristotélico], que podrían ser asociados con aspectos del rango social, pero no son, en el fondo, categorías de este tipo" (Halliwell, Aristotle's Poetics 268). En el mismo sentido de hacer hincapié en el aspecto moral del personaje dramático, García Bacca señala que la palabra ethos "significa unitariamente temperamento y moralidad, un componente anímico (temperamento) y otro moral (moralidad, positiva o negativa, virtud o vicio)" (García Bacca 19).

21 Tanto la tragedia como la comedia nacen de improvisaciones; "una, gracias a los que entonaban el ditirambo, y la otra, a los que iniciaban los cantos fálicos" (Aristóteles, Poética 139).

22 Presentar una acción, como dice García Yebra, "en el sentido de que, en el curso de la narración, él [Homero] se retira y cede la palabra a sus personajes" (257). Recordar que esto es lo que Aristóteles considera un ejemplo de imitación poética, teniendo como referencia a Homero (Aristóteles, Poética 221). 
hombres libres y educados y los esclavos incultos. Y pone como ejemplo de esta distinción dos manifestaciones de la comedia: la antigua y la nueva. En la primera, "la risa consistía en el lenguaje obsceno", mientras que en la segunda "es la insinuación" (149). Por lo tanto, una primera distinción entre ambos términos, considerando, como lo hace Halliwell, el rasgo común que los une como fuerzas críticas dirigidas contra un objetivo (Halliwell, Aristotle's Poetics 270), supone la exclusión del dolor y el daño de la esfera de lo cómico. Pues, como muchos conciben, el defecto y la fealdad expresados por Aristóteles para delimitar el ámbito de lo cómico se opone al error trágico que es destructivo y doloroso mediante la oposición entre hamartema y hamartía. "Una comedia adecuada", "debería entretener, no causar dolor. Finalmente, podemos notar al pasar que el error cómico (hamartema) es paralelo al error trágico (hamartía, cap. XIII) y la risa cómica a la compasión y el temor" (Hardison 105). Esto mismo se adecua al tipo de desenlace que Aristóteles propone, en el capítulo 13, como apropiado para la comedia. Aristóteles establece allí una jerarquía de los desenlaces de la tragedia: en primer lugar es adecuada a la tragedia el paso de la dicha a la desdicha (fábula simple); y solo en segundo lugar, al contrario de la opinión de algunos, sitúa la tragedia con estructura doble, la que "termina de modo contrario para los buenos y para los malos" (172). Este último desenlace involucra un placer "que más bien es propio de la comedia; aquí, en efecto, hasta los más enemigos según la fábula, como Orestes y Egisto, al fin se tornan amigos y se van sin que ninguno muera a manos de otro" (173).

Una segunda diferencia es establecida por Aristóteles en los capítulos 5 y 9. Allí la invectiva se relaciona con lo individual, mientras se considera a la comedia como una mímesis de acciones y caracteres generalizados. En el capítulo 5, Aristóteles menciona la composición de argumentos y fábulas de carácter general por parte de algunos poetas cómicos ${ }^{23} \operatorname{como}_{\text {opuesta a }}$

23 Dice Aristóteles: "Quién introdujo máscaras o prólogos o pluralidad de actores y demás cosas semejantes, se desconoce; pero el componer fábulas, Epicarmo y Formis. Esto, al principio, vino de Sicilia; pero de los atenienses fue Crates el primero que, abandonando la forma yámbica, empezó a componer argumentos y fábulas de carácter general" (143). Comentando este pasaje, García Yebra dice que no se sabe muy bien por qué Aristóteles atribuye a Crates la composición de fábulas y argumentos de carácter general, omitiendo a Cratino, quien es anterior y reconocido como superior y del que no se puede dudar que compuso argumentos bien estructurados. Como solución propone interpretar el pasaje ateniéndose al hecho del abandono de la forma yámbica. Si bien Cratino efectivamente estructuró argumentos de carácter general, éste no habría abandonado las invectivas personales (261-262); como se 
la forma yámbica. $\mathrm{Y}$ en el capítulo 9 propone la comedia como ejemplo de estructuración de las fábulas según los criterios de verosimilitud y necesidad, propios de la generalidad a la que tiende la poesía. Pues esta última, tal como se deduce de su definición de tragedia, tiene como objeto principal las acciones, de manera que no es imitación de personas. Así, el hecho de colocar nombres a los personajes una vez estructurado el argumento de manera general resulta accesorio. Sobre todo si consideramos que aquellos nombres pertenecen a personajes históricos. Pues la generalidad de la poesía, exime a la comedia de componer sus fábulas, como lo hacían los poetas yámbicos, "en torno a individuos particulares" (159). Y que, en el caso de la tragedia, si bien se atiene generalmente a "nombres que han existido" $(159)^{24}$, esto se hace, como dice García Yebra, con la finalidad de conseguir un refuerzo de verosimilitud (274), considerando que todo lo sucedido es prueba de lo posible, "pues no habría sucedido si fuera imposible" (159) ${ }^{25}$. En una interpretación particular, Heath, para quien no es incompatible la invectiva personal dentro de la universalidad del argumento cómico, sobre todo si efectivamente se separa el criterio ético del poético para evaluar la comedia, señala que así como el uso de nombres reales en la tragedia no compromete la universalidad del argumento trágico, tampoco el uso de nombres inventados en la comedia es una garantía de ella. En efecto, y sin ir más allá de sus argumentos para validar la incorporación de lo particular y dañino en lo cómico $^{26}$, el concepto de universalidad en Aristóteles es completamente

puede reconocer en la interpretación que Jaeger hace de su obra como ejemplo del verdadero yambo antiguo que tiene sus orígenes en la sátira política (329). Lo que da pie para suponer que la incorporación de individuos reales en la fábula no amenaza el carácter general de ésta.

24 Teniendo en mente, como dice García Yebra citando a Else, que Aristóteles, "igual que todos los griegos de la época clásica, creía en el carácter histórico de su mitología (275).

25 Esto también es un ejemplo de que la poesía, a pesar de haberse distinguido de la historia por no tratar con lo que ha sucedido (como lo hace la primera) sino con lo que podría suceder, puede incorporar cosas sucedidas siempre que se ajusten a lo verosímil y lo posible, que son los criterios por los cuales se rige la poesía.

26 Por una parte, la distinción entre la corrección política (que incluye la ética) y la poética en el capítulo 25 le permite a Heath argumentar a favor de una distinción entre los criterios para el humor en la interacción social cotidiana y los correspondientes a la representación cómica, que se encarga de imitar a hombres en acción moralmente inferiores. Desde su punto de vista, el hecho de que la poesía imite a hombres inferiores justifica, siguiendo el criterio de universalidad que trata sobre la relación entre agentes y acciones, la utilización de invectivas en la comedia, ya que sería algo que se esperaría de los caracteres imitados considerando sus cualidades éticas. Además, no considera que Aristóteles haya propuesto una 
independiente de la diferencia entre lo real y lo inventado y el punto crucial es más bien la naturaleza de la relación entre los agentes y sus acciones, es decir, su relación con base en los principios de verosimilitud y necesidad. De esta manera, los mismos criterios de verosimilitud y necesidad aplicables a las obras trágicas operarían para las obras cómicas. En palabras de Halliwell, "la fuerza crítica dirigida contra "el error y la deformidad"”, en la comedia "debería ser integrada dentro del diseño de una acción inteligible y coherente" (Halliwell, Aristotle's Poetics 271).

\section{LA FEALDAD DE LO CÓMICO COMO RASGO GENERAL DEL HOMBRE}

En el capítulo V de la Poética, Aristóteles se refiere a lo risible como una especie de "fealdad que no causa dolor ni ruina" (142). El lenguaje de este pasaje, según Halliwell, justifica la inferencia de que Aristóteles tiene en mente un amplio rango de posibilidades cómicas al momento de referirse a las "deficiencias", las que incluyen lo físico, lo social y material, además de lo específicamente ético; siempre y cuando "el dolor y la destrucción", que son parte del dominio de la tragedia, sean evitados" (Halliwell, Aristotle on comedy 180).

Para Butcher, lo universal en la poesía-término que incluye las deficiencias humanas de las que trata la comedia, como veremos más adelante- se relaciona directamente con lo "ideal" desde dos acepciones. Primero, como lo esencial opuesto a lo accidental y trivial. Una especie de universal que "responde a la verdadera idea del objeto que trasciende las limitaciones de

contraposición entre la invectiva y lo risible. Primero, porque piensa que, en el capítulo 4, la invectiva ( $p s o g o s)$ no está siendo usada en el sentido general de abuso, sino en un sentido semitécnico que cumple la función de dar cuenta de aquellas formas elementales de la poesía que imitan acciones inferiores, semejantes a los himnos y encomios. Estas formas no serían dramáticas a diferencia del Margites de Homero. Además, lo risible, según él, no es antitético a la invectiva como expresión de un "contenido abusivo", sino al contenido serio y elevado de la Ilíada y la Odisea, teniendo en vista que en el pasaje la argumentación tiende a establecer una analogía entre la comedia y el Margites y entre la Ilíada y la Odisea con la tragedia, "no con la relación entre el Margites y la comedia con la invectiva" (4). Y segundo, porque establece que la invectiva quedaría pobre de sentido si se considera antítesis de lo risible, ya que, citando las consideraciones que hemos visto de la Ética, este último muy a menudo implica el insulto y el daño. 
lo individual" (370). Y segundo, en virtud del proceso que significa que un objeto se deshaga de sus formas accidentales para asumir lo esencial, todo objeto idealizado resaltará en belleza y perfección. Así, bajo este punto de vista, como él mismo expresa, la comedia, al no representar las formas más nobles y justas de su objeto, no podría ser considerada como una expresión de lo universal o esencial. No obstante, Butcher legitima los defectos e imperfecciones de la comedia al considerarlos partes constituyentes del hombre, como características permanentes de la humanidad. La fealdad de la comedia, asociada a un amplio rango de deficiencias humanas ${ }^{27}$, al ingresar en la acción de la comedia, se embellece al adquirir la cualidad de lo general o universal. La representación cómica no exhibiría lo malo en su naturaleza real sino como algo de lo cual uno reiría más que odiaría. Lo malo mostrado en su naturaleza esencial sería feo e implicaría, ateniéndonos al elemento de odio en su recepción, dolor. No así si es expuesto en la acción de la comedia donde se transformaría en insignificante y ridículo, siendo purgado de la risa triunfal o maligna ${ }^{28}$. El mérito de Aristóteles, para Butcher, mediante su definición incompleta de lo cómico, habría sido dar cuenta de lo risible puro. En un sentido similar, Olson, quien funda su teoría de lo cómico sobre criterios aristotélicos, expresa que solo lo propiamente ridículo (lo que no está asociado ni a la envidia ni al dolor, por ejemplo ${ }^{29}$ ) debería ser ridiculizado. Solo de esta manera la comedia nos ofrecería un ridículo con aspecto universal manifestado a través de lo particular. Así, por el hecho de reconocer lo ridículo como propiamente ridículo, la comedia sería una fuente de placer mediante el aprendizaje. De ahí, también, que el conocimiento en la obra poética se encuentre ligado a un componente ético (57-58). Como expresa Reckford, interpretando el sentido de la representación en la comedia de las exageraciones $\mathrm{y}$ distorsiones de la conducta llevadas a cabo por sus personajes, y pensando que el conocimiento no es solo de una realidad empírica sino también moral,

$27 \quad$ “...de acuerdo a Aristóteles, la cualidad que provoca la risa es una cierta fealdad, un defecto o deformidad. Aquellas palabras, aplicables principalmente a la fealdad física, lo desproporcionado, lo asimétrico, incluiría las flaquezas, locuras, y debilidades de la naturaleza humana, siendo distinguidas de sus más graves vicios o crímenes” (Butcher 375).

28 En la comedia, tal como expusimos anteriormente, el error o defecto del héroe no es trágico (hamartema), o sea, carece de pathos (acción destructiva o dolorosa).

${ }_{29}$ Ejemplos concretos de estos sentimientos mezclados con lo ridículo serían los chistes que revelan agresiones. Pues sentir aversión del objeto ridiculizado muchas veces se encuentra asociado al dolor de reconocer que ese objeto tiene un valor que no se está dispuesto a admitir (Olson 57). 
las desviaciones presentadas en escena nos permiten reconocer la norma racional y moral apropiada (370-371). Esto tiene una directa relación con la interpretación de Halliwell sobre lo risible como una especie de lo vergonzoso (Halliwell, The Poetics of Aristotle 36). Lo cómico, para él, conserva una base y un sentido crítico al presentar varios tipos de deficiencia humana. Estas últimas corresponderían a aquellas actitudes sociales o públicas que son desaprobadas ${ }^{30}$. Para él, la cultura griega antigua tuvo una alta sensibilidad para la amonestación y el deshonor público. Lo que implica una evaluación de la deficiencia de acuerdo con las normas compartidas de una sociedad ${ }^{31}$. La risa, por lo tanto, en los comienzos del género, habría estado dirigida

30 Este sentido social de las deficiencias representadas por la comedia se opondría a la visión idealista de Butcher que las considera como "defectos permanentes de nuestra humanidad común”. Según Halliwell, el idealismo de Butcher que interpreta los universales poéticos como inmutables y trascendentes, es contrario a la concepción histórica de Aristóteles, quien concibe, en la Retórica, los cánones de necesidad y verosimilitud, de acuerdo al "trasfondo personal, social, político y cultural de las audiencias individuales" (Halliwell, The aesthetics of Mimesis 197).

31 Tanto Olson como Butcher, en el mismo sentido, consideran que el fundamento de lo ridículo es un principio compartido fundado en la semejanza. Ya hemos visto el rol que cumple esta última dentro de la mímesis poética como factor de aprendizaje basado en el reconocimiento. Butcher, quien identifica lo ridículo con lo incongruente, funda a éste último en el descubrimiento de una semejanza o desemejanza inesperada que no produce ninguna risa triunfal o maligna (376). Mientras que Olson considera la semejanza como el modelo por el cual reconocemos los defectos que nos hacen despreciar a una persona, sus actos o sus discursos (32-33). Otra función de la semejanza en la comedia se desprendería de su rol en la caricaturización. Para Butcher, lo universal de la comedia, dentro de su concepción dialéctica hegeliana, peca de exceso al no representar una relación armónica entre lo particular y lo general. De esta manera, concluye que el poder generalizador de la comedia consiste en subsumir lo individual dentro de lo general, consiguiendo solo una parcialidad en la representación. No sucede lo mismo con la tragedia, que logra representar a través de lo particular lo general; de la misma manera que el humor de la comedia moderna. Este método de generalización de la comedia crea caricaturas, ya que hace que los elementos particulares funcionen como totalidad sobre el personaje; de la misma manera que los describe Bergson en su libro La risa, como encarnaciones de un vicio o pasión dominante, aislada y desconectada con el resto de la vida, sobreponiéndose como algo mecánico. Un ejemplo de aquello es el uso de la metáfora en la comedia aristofánica, tal como nos la muestra Olson. En la metáfora, una vez que se tiene conciencia de la semejanza entre dos partes, se conciben aquellas como totalidades; una en reemplazo de la otra. De esa forma, la identificación así concebida no deja espacio para nada más: "de los rosados dedos" hace del alba una doncella; "de los dedos de zanahoria" hace del alba una criada. Y Cleón y Brásidas [políticos de Atenas y Esparta, respectivamente, que se oponían a la concertación de una paz entre ambas polis] se convierten en morteros y nada más (97-98). 
contra objetivos -que involucraban a personas reales- considerados como vergonzosos. Para, posteriormente, expresar las deficiencias o la fealdad a través de tipos, como se puede deducir del ejemplo puesto por Aristóteles de la máscara cómica contrahecha. Por ende, este ejemplo sirve para mostrar nuevamente la diferencia entre lo propiamente cómico y el modo yámbico. Al implicar una identidad ficcional, la máscara cómica expresaría la intención de remitir a rasgos humanos cuyo sentido es general o universal. "Parodiar a un individuo feo, al contrario, sería considerado por Aristóteles como éticamente ofensivo; y ser invitado por la comedia a satisfacer tal risa sería por lo tanto combinar un error poético con uno ético" (Halliwell, The Poetics of Aristotle 87). El error poético sería no representar un personaje universal, mientras que el ético sería burlarse de alguien particular. Ambos criterios están relacionados en la medida en que consideran lo particular como opuesto a los estándares de lo verdaderamente cómico. Así, a través de la delimitación de lo risible, excluyendo lo dañino y doloroso, y por lo tanto proponiendo un componente ético para su comprensión, Aristóteles establece su estatuto general acorde a la idea de la mímesis poética que, rigiéndose por los principios de verosimilitud y necesidad, nos entrega, a través de un mundo imaginado, una experiencia inteligible (y por ende, placentera) de la realidad.

\section{CONCLUSIÓN}

En síntesis, las diversas reflexiones de Aristóteles en torno al género cómico se insertan dentro de un esquema de desarrollo que tiene como criterio para evaluar sus puntos de inflexión (el paso de la forma yámbica a la comedia propiamente) la idea de generalidad o universalidad. De los intentos tempranos de tratar con aquellos aspectos defectuosos del carácter, relacionados con individuos particulares y expresados a través de una forma carente de argumento general, a una representación generalizada marcada por un tipo de humor que tiende a implicar un componente moral en oposición al lenguaje impúdico de la sátira personal. Al contrario de la tragedia,

Aristóteles habría sentido que el momento de la comedia llega en el siglo IV, no en el V. A pesar de la redefinición de los objetivos y métodos de la comedia que atribuyó a Crates, él habría considerado, algunas veces, la antigua comedia de Eupolis, Cratino, y Aristófanes, con sus chistes y acciones groseras, como un tipo de retroceso atávico 
al período pre-crático de sátira descuidada, improvisada e inartística (Reckford 373).

Como señala Olson, todos aquellos elementos farsescos y satíricos de la comedia Antigua fueron reemplazados por aspectos moralizadores en la Nueva. Y los argumentos (sobre todo si pensamos en la comedia aristofánica) de carácter fantástico fueron desplazados por aquellos basados en la probabilidad natural (103). De esta manera se concluye que, con mayor probabilidad, el ideal cercano de comedia, según lo expuesto en la Poética, correspondería a la comedia de la segunda mitad del siglo IV, que tiene como referente la obra de Menandro.

\section{BIBLIOGRAFÍA}

Aristóteles. Retórica. Madrid: Alianza, 2002.

Aristotle. "Politics". Trad. Jonathan Barnes. Complete Works (Aristotle). Princeton: Princeton

University Press, 1991.

Aristóteles. Ética a Nicómaco. Madrid: Alianza, 2005.

Poética. Trad. Valentín García Yebra. Madrid: Gredos, 1974.

Butcher, S. H. Aristotle's theory of poetry and fine arts. London: Macmillan and co, limited, 1923.

García Bacca, Juan David. "Introducción a la Poética”. La poética de Aristóteles. México D.F: Editores mexicanos unidos, 1996.

García Yebra, Valentín. "Notas a la traducción española”. Poética. Madrid: Gredos, 1974.

Gomá Lanzón, Javier. Imitación y experiencia. Barcelona: Crítica, 2005.

Halliwell, Stephen, "Aristotle on Comedy". The Cambridge History of Literary Criticism,

Vol. I. Cambridge: Cambridge University Press, 2008. 179-183. Aristotle's Poetics. Chicago: University of Chicago Press, 1998.

The aesthetics of Mimesis. Princeton: Princeton University Press, 2002.

The Poetics of Aristotle. London: The University of North Carolina Press, 1987.

Hardison, O.B. “A Commentary on Aristotle's Poetics". Aristotle's poetics. A translation and commentary for students of Literature. New Jersey: Prentice-Hall, 1968.

Heath, Malcolm. “Aristotelian Comedy". White Rose Research Online. Octubre 2013. http:// eprints.whiterose.ac.uk/522/1/heathm17.pdf

Jaeger, Werner. Paideia: los ideales de la cultura griega. México D.F: Ed. FCE, 2006.

Lukács, Georg. Problemas del realismo. México D.F: FCE, 1966.

Potolsky, Matthew. Mimesis. New York: Routledge, 2006.

Olson, Elder. Teoría de la comedia. Barcelona: Ariel, 1978. 
Reckford, Kenneth J. "Aristotle and the Split in Comedy". Aristophanes'Old-and-New Comedy. London: The University of North Carolina Press, 1987.

Tatarkiewicz, Wladyslaw. Historia de la estética: I La estética antigua. Madrid: Akal, 2000. 